\title{
A SUSTENTABILIDADE E A CADEIA PRODUTIVA HOTELEIRA: UM ESTUDO DE CASO NO JW MARRIOTT, RIO DE JANEIRO
}

\begin{abstract}
SUSTAINABILITY AND THE HOTEL PRODUCTION CHAIN: A CASE STUDY OF THE JW MARRIOTT, RIO DE JANEIRO
\end{abstract}

\section{LA SOSTENIBILIDAD Y LA CADENA PRODUCTIVA HOTELERA: UN ESTUDIO DE CASO EN EL JW MARRIOTT, RIO DE JANEIRO}

\section{Rodrigo Amado dos Santos}

Docente - Universidade Federal Rural do Rio de Janeiro, Curso de Bacharelado em Hotelaria.

Doutorando em Sistemas de Gestão Sustentáveis - Universidade Federal Fluminense (UFF). profrodrigoamado@gmail.com Tamires Chagas Matschuck Bacharel em Hotelaria - Universidade Federal Rural do Rio de Janeiro (UFRRJ). tamiresmatschuck@yahoo.com.br Data de Submissão: 23/02/2015

Data de Aprovação: 02/06/2015

RESUMO: As fundamentações, os valores, os princípios e as condutas do desenvolvimento de uma prática turística mais sustentável se mostram como o objeto central da análise desse trabalho. Em específico, aqui os autores buscarão enfatizar de que forma propostas de sustentabilidade atreladas ao segmento turístico/hoteleiro devem assumir uma conotação estratégica, participativa e descentralizada que permita atender as necessidades atuais e futuras do trade turístico, de seus stakeholders, comunidades autóctones e turistas, sem deixar de lado as particularidades e as fragilidades a serem apreciadas e monitoradas nas relações de uso que serão constituídas junto às dimensões ambientais, sociais, econômicas, políticas, culturais e espaciais que sustentarão sua cadeia produtiva. Assim, reconhecendo a capacidade de intervenção temporal e territorial, positiva e/ou negativa, que os empreendimentos hoteleiros perpetram e difundem entre tais personagens e dimensões, o presente trabalho apresentará um estudo de caso pautado por pressupostos qualitativos, realizado no Hotel JW Marriott Rio de Janeiro, expondo uma mensuração, por meio da planilha SWOT, de suas práticas, condutas, valores e programas atrelados à sustentabilidade. Desse modo, por meio de entrevistas semiestruturadas e análises in loco, os autores identificaram ações que vão além dos preceitos do Triple Bottom Line e que acabam por legitimar o hotel como uma empresa sustentável. 
Palavras-chave: Desenvolvimento Sustentável. Hotel JW Marriott Rio de Janeiro. Gestão Hoteleira.

ABSTRACT: The foundations, values, principles and proceedings related to the development of a more sustainable tourism practice are the central object of this paper. Specifically, the authors seek to emphasize how sustainability proposals linked to the tourism and the hotel sector should take on a strategic, participatory and decentralized connotation that enables them to meet the current and future needs of the tourism trade, its stakeholders, local communities, and tourists, without forgetting the peculiarities and weaknesses that need to be observed and monitored in the relations of use that will be established in the environmental, social, economic, political, cultural and special dimensions that support its production chain. Thus, recognizing the temporal and territorial intervention capacities, both positive and negative, that are perpetrated by hotel establishments and spread among the different characters and dimensions, this paper presents a case study, based on qualitative assumptions, conducted at the JW Marriott Hotel Rio de Janeiro, exposing a measurement, through a SWOT analysis of its practices, proceedings, values and programs linked to sustainability. Thus, through semi-structured interviews and analysis in loco, the authors identified actions that go beyond the precepts of the Triple Bottom Line, and that end up legitimizing the hotel as a sustainable company.

Keywords: Sustainable Development. Hotel JW Marriott Rio de Janeiro. Hotel Management. Sustainable Development.

RESUMEN: Las fundamentaciones, los valores, los principios y las conductas en el desarrollo de una práctica turística más sostenible se plantean como el objeto central de análisis de este trabajo. En particular, aquí los autores harán hincapié en la forma en la que las propuestas de sostenibilidad vinculadas al segmento turístico/hotelero deben asumir una connotación estratégica, participativa y descentralizada que permita atender a las necesidades actuales y futuras del trade turístico, de sus stakeholders, comunidades autóctonas y turistas, sin dejar de lado las particularidades y las fragilidades que serán apreciadas y monitoreadas en las relaciones de uso que serán constituidas en las dimensiones ambientales, sociales, económicas, políticas, culturales y espaciales que sostendrán su cadena productiva. Así, reconociendo la capacidad de intervención temporal y territorial, positiva y/o negativa, que los emprendimientos hoteleros perpetran y difunden entre tales personajes y dimensiones, el presente trabajo presentará un estudio de caso pautado por presupuestos cualitativos, realizado en el Hotel JW Marriott Rio de Janeiro, exponiendo una mensuración, por medio de la planilla SWOT, de sus prácticas, conductas, valores y programas vinculados a la sostenibilidad. De ese modo, por medio de entrevistas semiestructuradas y análisis in loco, los autores identificaron acciones que van más allá de los preceptos del Triple Bottom Line y que acaban por legitimar al hotel como una empresa sostenible.

Palabras clave: Desarrollo Sostenible. Hotel JW Marriott Rio de Janeiro. Gestión Hotelera.

INTRODUÇÃO 
produzidos por parte de empresas, governos, instituições não governamentais e sociedades, junto aos recursos naturais e culturais que sustentam não só a lógica do sistema capitalista moderno, como também preceitos socioculturais específicos à sociedade contemporânea. Documentos como Relatório de Brundtland - Our Common Future (1987), a Agenda 21 (1992) e a Carta da Terra (1997) transpareceram a necessidade dessa mesma sociedade em rever e readaptar suas relações com seu meio ambiente (NOBRE, 2002), mostrando-se, portanto, imprescindível a criação de políticas normativas específicas capazes de estabelecer parâmetros, diretrizes, valores e princípios capazes de guiar e enaltecer gestões e práticas mais conscientes, responsáveis e sustentáveis. Neste cenário, a cadeia produtiva do turismo jamais deverá ficar à margem desse movimento, visto que cada vez mais há uma compreensão sobre a relação de interdependência entre o desenvolvimento das atividades turísticas e as dimensões socioculturais, econômicas, políticas, espaciais e ambientais da sustentabilidade (SACHS, 2000; PEREZ; DEL BOSQUE, 2014; SLOAN; LEGRAND; KAUFMANN, 2014).

Assim, como parte integrante da cadeia produtiva do turismo, o segmento hoteleiro será visto aqui como "engrenagem" fundamental ao surgimento, ao crescimento e à propagação da atividade turística e justamente por isso deve assumir sua responsabilidade perante os impactos causados ao meio ambiente, à sociedade e aos stakeholders envolvidos em seu processo de planificação e operacionalização (CHEN, 2015; FRAJ, MAMUTE; MELERO, 2015). Desta forma, projetos e iniciativas que promovam uma gestão participativa capaz de integrar e contemplar justa e responsavelmente as necessidades oriundas da comunidade, do meio ambiente, do mercado e dos turistas começaram a ser idealizados por empresas hoteleiras - dentre as quais se destacam as redes Marriott, Accor, Hilton e Windsor - com o intuito de se estabelecer um ponto de equilíbrio entre a sanção de suas necessidades e as peculiaridades, as particularidades e as fragilidades territoriais na quais esses atores estão cercados. Dito isso:

(...) a United Nations World Tourism Organization define a sustentabilidade no contexto turístico enquanto um conjunto de princípios que se referem aos aspectos econômicos, ambientais e socioculturais relacionados ao desenvolvimento do turismo, e uma balança adequada [que] deve ser estabelecida entre essas três dimensões para se garantir a sustentabilidade a longo prazo. Inspirados nesse preceito, [define-se] sustentabilidade hoteleira 
enquanto um conjunto de estratégias mercadológicas que encontram as necessidades atuais dos hóspedes, dos stakeholders e dos operadores turísticos sem comprometer a habilidade de apreciação futura destes mesmos indivíduos em se beneficiar desses mesmos serviços, produtos, recursos e experiência. Essa definição leva em consideração o caráter intergeracional, um dos primeiros princípios da sustentabilidade. (SLOAN; LEGRAND; KAUFMANN, 2014, p.53).

Para contribuir com benefícios à comunidade, além de minimizar os impactos negativos oriundos de sua operacionalização, os autores defendem a ideia de que os empreendimentos hoteleiros, independentemente de suas tipologias, portes e classificação, necessitarão pautar seus planejamentos com base nas matrizes gerenciais - da eficiência, da escala, da equidade, da autossuficiência e da ética - enaltecidas no Relatório de Bruntland (ASCERALD, 2001). Essas matrizes, que sustentamboapartedos princípiosnormativosexpostos peloschamadosindicadores de sustentabilidade, apontam o caminho que deve ser traçado pelo setor hoteleiro e por toda empresa relacionada à cadeia produtiva do turismo, de forma a se projetar relações ecoeficientes, socialmente responsáveis e economicamente justas a todo e qualquer indivíduo e/ou organização que se relaciona ou é influenciado por essa cadeia produtiva (SANTOS; EMILIANO; PAGAMISSE, 2012).

Desta maneira, ao longo deste trabalho será enfatizado que, para o desenvolvimento sustentável ocorrer em âmbitos hoteleiros/turísticos, é necessário que suas ações sejam planejadas de forma a abranger as necessidades econômicas, socioculturais e ambientais de sua territorialidade, além de se buscar a satisfação, tanto dos desejos e das necessidades dos visitantes, quanto dos moradores, dos empreendedores e dos demais stakeholders, tentando estipular um equilíbrio entre os tais anseios e o ponto de saturação/degeneração dos recursos naturais e culturais utilizados (PEREZ; DEL BOSQUE, 2014; CHEN, 2015). Destarte, as acepções relacionadas ao turismo sustentável devem ser vistas como um "norteador" para o gerenciamento dos recursos, das infraestruturas e das superestruturas dos quais a cadeia produtiva turística depende. A partir disso, seria possível conceber as necessidades econômicas, sociais e estruturais requisitadas sem negligenciar a integridade cultural, os processos ecológicos e a diversidade biológica de determinada região (UNEP; UNWTO, 2005).

Por esta perspectiva, uma das propostas desse artigo é enaltecer e difundir a necessidade de se estabelecer um processo contínuo e gradativo acerca da relação estratégica entre a atividade turística, os meios de hospedagem, 
a sociedade contemporânea e os preceitos que sustentam a lógica do desenvolvimento sustentável. Exposto isso, os aspectos que tangenciam o desenvolvimento estratégico, gerencial e operacional da hotelaria devem ser enveredados e imersos, visto que esses estabelecimentos se apresentam como um dos setores fundamentais que sustentam o desenvolvimento e a lógica operacional das atividades turísticas, estando diretamente relacionados à boa parte dos impactos causados ao meio ambiente e às comunidades locais, principalmente pela construção de grandes e imponentes infraestruturas, bem como a inserção de equipamentos, produtos e serviços que tendem a manipular e descaracterizar distintas características de uma localidade (LEMOS, 2001).

Por meio de sua aplicabilidade, monitoramento e avaliação, as gestões sustentáveis suscitam investimentos por parte do empreendimento na manutenção e na preservação, dos recursos naturais, da localidade e da sua cultura, além da opção pela mão de obra local, o que acarretaria, assim, a oportunidade de emprego e renda. Em consequência, o empreendimento efetivase na localidade e constrói uma imagem alicerçada em princípios participativos que denotariam credibilidade à sua marca (HAN; YOON, 2015), além de desenvolver suas atividades de forma a preservar os recursos fundamentais para o estabelecimento. Essa filosofia possibilita que outras gerações possam também desfrutar dos prazeres proporcionados por suas práticas, oferecendo, portanto, ao turista uma "dose" de sensibilização que vai além da experiência com os serviços prestados: a formação do sujeito ecológico.

Nesse sentido, os autores objetivam, a partir do desenvolvimento desse artigo, "chamar atenção" no que tange aos aspectos relacionados à abrangência e à difusão da temática "sustentabilidade" perante os processos gerenciais e operacionais de meios de hospedagem, independentemente de suas tipologias, segmentos de atuação, porte e classificação. Haverá aqui um convite reflexivo para que os leitores pensem a sustentabilidade além das premissas ambientais, sociais e econômicas que a sustentam. Existe aqui a perspectiva de se instigar acadêmicos, gestores e profissionais da área a pensarem também a relevância que aspectos culturais, políticos e espaciais (SACHS, 2000) possuem nesse processo, formando, assim, seis dimensões a serem levadas em consideração durante a análise dos impactos e dos retornos a curto, médio e longo prazo, a 
todo e qualquer indivíduo, grupo social e/ou instituição que forem influenciados, direta e/ou indiretamente, por essa cadeia produtiva.

Exposto isso, a proposta desse artigo se fundamenta na exposição dessas prerrogativas em um estudo de caso realizado no JW Marriott Rio de Janeiro. Assim, a ótica da sustentabilidade aqui descrita objetivará compreender como ações gerenciais e operacionais devem se entrelaçar com as esferas sociais, culturais, ambientais, espaciais e econômicas de uma dada territorialidade, com o intuito de se pontuar suas influências acerca da construção não só da imagem empresarial, bem como do preceito de "qualidade percebida" a ser visto em produtos, serviços, infraestrutura, equipamentos e atendimentos. Assim, um aspecto relevante de ser dito é o fato de esse trabalho buscar a apreciação de uma cultura organizacional (GALPIN; WHITTINGTON; BELL, 2015), evidenciando como essa se encontra pautada em reflexões holísticas que permeiam a temática da sustentabilidade hoteleira e que precisam estar incutidas nas missões, visões, princípios e valores de um estabelecimento turístico.

\section{ASPECTOS METODOLÓGICOS:}

Para a concretização do artigo, admitindo seu caráter exploratório, os autores realizaram uma pesquisa qualitativa, pautada nos pressupostos de Robson (2011), a qual permitiu descrever condutas e significados peculiares ao universo hoteleiro no que tange às apropriações dos princípios, das condutas e dos valores relacionados à temática de desenvolvimento sustentável. Dessa maneira, essa pesquisa teve o intuito de conhecer, de maneira pormenorizada, características, peculiaridades, fragilidades, inter-relações e interdependências entre as premissas estratégicas do desenvolvimento sustentável e as especificidades gerenciais e operacionais que conduzirão sua aplicabilidade em meio à cadeia produtiva hoteleira.

Deste modo, julga-se importante mencionar que a escolha pela análise qualitativa se deve por essa ser um instrumento metodológico pertinente para se aferir, decifrar e expor as intrigantes, densas e complexas relações, significados e representações (HAIR JR. et al., 2009) que podem ser abstraídos do prisma 
da sustentabilidade hoteleira. Além disso, levando-se em consideração os princípios de validade, coerência e credibilidade científica (SINGLETON JR., 2010), os autores desenvolveram um estudo de caso, acreditando que tal método propiciaria uma análise crítica mais densa de uma temática que se mostra indubitavelmente relevante à cadeia produtiva hoteleira contemporânea. Afinal de contas, o estudo de caso é visto como uma "estratégia de pesquisa, [que] busca a compreensão de fenômenos sociais contemporâneos complexos" (YIN, 1989, p.14) e que "permite que a investigação empírica mantenha características holísticas e significativas de eventos da vida real" (ROTHAMAN, 1994, p. 246).

Como meio de coleta de informações, pela lógica qualitativa, os autores realizaram entrevistas com o colaborador responsável pela gestão de políticas e programas sustentáveis do hotel J.W. Marriott Rio de Janeiro. Caracterizada como entrevista semiestruturada, o procedimento deu-se com apoio de um roteiro de perguntas idealizado a partir dos conceitos expostos e da elaboração do estado da arte desse artigo, que foi possível graças aos processos de levantamento bibliográfico e a construção de sua fundamentação teórica. No que tange aos artigos internacionais apresentados como base referencial, foram obtidos por meio de um motor de busca específico: Scopus. Através desse instrumento de busca, pleiteou-se a apresentação de discursos recentes que pudessem expor as especificidades e as particularidades que a temática da sustentabilidade assume no cenário turístico/hoteleiro contemporâneo.

Dito isso, apenas com o intuito de corroborar e validar a importância dos debates proporcionados por essas obras, julga-se relevante mencionar que as mesmas são provenientes de revistas acadêmicas de destaque, sendo essas: a Journal of Retailing and Consumer Services (Qualis A1), Journal of Business Ethics (Qualis A1), Corporate Governance (Qualis A2), Tourism Management (Qualis B1), International Journal of Hospitality Management (Qualis B1), a Worldwide Hospitality and Tourism Themes (Qualis B1), Knowledge and Process Management (Qualis B1).

Assim, para a apreciação dos dados obtidos a partir dessas entrevistas, foram levados em consideração os preceitos que sustentam a lógica das pesquisas em ciências sociais, observando-se todas as particularidades e especificidades que essa análise (ROBSON, 2011) demanda. Os autores perceberam a importância de poder caminhar, como dirá Von Simson apud Queiroz (1998), do "indizível 
ao dizível", ao assumir a importância de se tentar registrar aquilo que ainda não foi visto, seja por meio de uma documentação e/ou um ponto de vista ainda não explorado, por meio dos semblantes, dos sentimentos, das conotações por detrás das falas de personagens que vivenciaram as histórias e as relações de todo o ambiente que circunda este empreendimento.

\section{FUNDAMENTAÇÃO TEÓRICA:}

Atualmente, muito tem se falado sobre a questão da sustentabilidade e da sua difusão em todos os campos da sociedade e da ciência. Desde a década de 70, presencia-se a disseminação desse conceito, além da necessidade da inserção de seus valores, princípios, normativas e diretrizes nos debates estratégicos das esferas públicas e privadas da sociedade contemporânea (NOBRE, 2002).

Nesse sentido, Veiga apud Oliva (2005) discorre que, em sua origem, a sustentabilidade relacionava-se apenas aos cuidados relativos à exploração de recursos naturais, havendo assim uma preocupação ímpar perante a proteção dos ecossistemas. Contudo, nos últimos anos, questões sociais, econômicas, culturais e políticas começaram a fazer parte do discurso de desenvolvimento sustentável, exatamente como pôde ser visto na "Carta da Terra" apresentada na II Conferência das Nações Unidas em 1992, no Rio de Janeiro, que tratou o aspecto socioeconômico como prerrogativa fundamental à proposta da sustentabilidade contemporânea (ASCERALD, 2001). Assim, desde que essa acepção foi aceita e difundida por instituições internacionais, a sustentabilidade se firma como uma proposta de desenvolvimento que "combina eficiência econômica com justiça social e prudência ecológica" (JACOB, 2003, p. 185). Deste modo, na medida em que tal conceito se solidifica e se enraíza nas bases econômicas desta sociedade, Donaire (1999, p. 13) chamará atenção ao fato de as:

[...] empresas que até então eram vistas apenas como instituições econômicas com responsabilidades referentes a resolver os problemas econômicos fundamentais (o que produzir, como produzir e para quem produzir) têm presenciado o surgimento de novos papéis que devem ser desempenhados, como resultado das alterações no ambiente em que operam. 
Para muitas empresas, a adesão de práticas gerenciais e operacionais mais sustentáveis passou a ser não apenas uma preocupação com o futuro da humanidade, mas sim com o próprio futuro organizacional. Prova disso pode ser observada em uma pesquisa realizada junto a:

[...] líderes de mercado, conduzida pela The Economist (2008), [onde] menos de $04 \%$ dos gerentes avaliados consideram que a responsabilidade socioambiental seja um "desperdício de tempo e dinheiro". (GALPIN; WHITTINGTON; BELL, 2015, p. 01-02).

Deste modo, possuir políticas de sustentabilidade se mostra como elemento primordial à estratégia de desenvolvimento corporativo, em especial ao segmento turístico, já que "a indústria da hospitalidade está adotando essa abordagem enquanto um modo efetivo para promover seus negócios em um mundo cada vez mais saturado de marcas e logotipos empresariais" (MARTINEZ; PEREZ; DEL BOSQUE, 2014, p. 48).

Por tais motivos, o tema sobre gestões turísticas sustentáveis tem sido amplamente discutido (CHOU, 2014; MARTINEZ; PEREZ; DEL BOSQUE, 2014; SLOAN; LEGRAND; KAUFMANN, 2014; CHEN, 2015; FRAJ; MATUTE MELERO, 2015) na sociedade contemporânea. Dentre as inúmeras justificativas que suportam preceitos, condutas e valores sustentáveis, uma que começa a ganhar maior notoriedade frente aos gestores hoteleiros é a questão da imagem. Afinal de contas, modelos de gestão sustentáveis possibilitam uma maior e melhor captação de clientes que se mostram interessados em consumir produtos, serviços, infraestruturas e equipamentos eco-amigáveis (HAN; YOON, 2015). Além disso, outro ponto difícil de ser ignorado é ilustrado na fala de Singh apud Ghosh, Siddique e Gabbay (2003, p.39) quando afirma que "nenhum desenvolvimento turístico, independentemente de sua grandeza, prosperará se não alicerçar suas práticas em preceitos sustentáveis, respeitando-se as necessidades e aspirações autóctones".

Diante desse cenário, os autores desse trabalho acreditam que o segmento hoteleiro se apresenta como um dos ícones responsáveis por introduzir, disseminar, orientar e guiar modelos de gestão mais sustentáveis, devido a sua força e representatividade perante os demais elementos que constituem o 
Sistema Turístico (BENI, 2007). A exemplo disso tem-se a Rede ACCOR, que por meio de seu programa Planet 21 atingiu marcas consideráveis no contexto do desenvolvimento sustentável: $68 \%$ de seus hotéis dão preferência à compra de produtos locais, promovendo e incentivando o aspecto da intersetorialidade local junto à produção de seus serviços; $83 \%$ de seus hotéis baniram do cardápio a utilização de animais marinhos em processo de extinção; $80 \%$ dos gerentes da rede foram recrutados na própria empresa, aspecto esse que demonstra o reconhecimento e a valorização de seu colaborador; e 6\% destes estabelecimentos utilizam energias renováveis (ACCOR, 2014).

Paralelo a essa vertente, é notório que a hotelaria vem se desenvolvendo "a passos largos" nos últimos anos, se expandindo por várias regiões e destinos turísticos do território brasileiro. Prova disso, é a expectativa de crescimento estruturada em torno de sua operacionalização. Acredita-se que nos próximos dez anos tal esfera da cadeia produtiva do turismo ganhará mais 192.700 unidades habitacionais (UH's), categorizadas em ao menos duas estrelas e que se juntarão às 270.500 desta mesma categoria, além das 5.200 que já se encontram em construção. Some-se a tal patamar quantitativo, levando-se em consideração todo e qualquer tipo de estabelecimento que oferte a prática da hospedagem, as já 4.645.000 de UH's já existentes no Brasil (RIBEIRO, 2013).

Observando apenas a rede hoteleira da cidade do Rio de Janeiro, percebe-se a expansão ocorrida nos últimos anos. De acordo com a Agência de Promoção de Investimentos do Rio de Janeiro (2013), a cidade carioca possui 32.425 UH's disponibilizadas em hotéis, motéis, pousadas, albergues e apart-hotéis. Além destas, há uma perspectiva de crescimento de $47 \%$ até meados de 2015 , ou seja: 15.387 UH's a mais previstas em 70 novos projetos que, conforme a agência, já se encontram em construção, licenciados ou em análise pela Secretaria Municipal de Urbanismo (AGÊNCIA DE PROMOÇÃO DE INVESTIMENTOS DO RIO DE JANEIRO 2013).

Por conseguinte, pela obrigatoriedade de se ampliar e proteger as oportunidades para o futuro hoteleiro, sem que, como ressalta Beni (2006), não haja a possibilidade do "turismo consumir o turismo, há a necessidade de que esse setor se adéque à parâmetros, valores e condutas sustentáveis, 
projetando-os em suas ações estratégicas, táticas e operacionais de forma a se atender os anseios e as expectativas de sua tríade turística, sem deixar de lado as questões relativas à proteção dos recursos naturais e culturais". Dentre essas ações, Sloan, Legrand e Kaufmann (2014) ressaltam a importância de propor a satisfação das necessidades básicas da comunidade autóctone. Já Lander apud Escobar (2005) propõe em sua abordagem a preocupação com as futuras gerações por meio de um consumo controlado dos recursos naturais e culturais. A proposição de uma gestão participativa é proposta por Bartholo, Sansolo e Bursztyn (2009) e a realização de programas educacionais e de qualificação, visando sensibilizar colaboradores, comunidade e sobre a importância desta temática é proposta por Neves Filho (1999).

Fica evidente que empreendimentos hoteleiros, independentemente de sua classificação e/ou tipologia, precisam estar mais atentos a este cenário, propondo uma inserção ininterrupta de valores e práticas sustentáveis às suas óticas gerenciais. Sendo assim, crê-se que esses estabelecimentos necessitam criar e implementar um plano estratégico em que estejam inseridas diretrizes sustentáveis aplicáveis à sua realidade e que trarão retornos positivos não apenas ao empreendimento, mas que também satisfaçam:

[...] os interesses dos empregados (benefícios sociais e voluntariado), dos clientes (acessibilidade física, oferta comercial saudável, etc.), dos fornecedores (código de conduta e compras responsáveis) e assim por diante. Paralelamente, as companhias também deverão projetar melhores práticas ambientais e econômicas de acordo com as preocupações específicas de seus stakeholders. (PEREZ; DEL BOSQUE, 2014, p. 201).

Com base nessa perspectiva, os gestores hoteleiros nacionais poderiam utilizar como referência as normativas estipuladas por entidades, programas e/ou indicadores já consolidados no cenário internacional, no que tange à elaboração, à aplicação e à validação de ações que comportem a questão da sustentabilidade no universo representativo da hotelaria. Dentre esses instrumentos, apenas a título de nomeação, julga-se relevante destacar: o Green Keye o Blue Flag, ambos desenvolvidos pela Foundation Environmental Education (FEE); o Global Sustainable Tourism Council, que apresenta as especificidades de um planejamento efetivo que priorize questões sociais, econômicas, ambientais 
e culturais no escopo de desenvolvimento proposto por empreendimentos hoteleiros e turísticos; além, é claro, dos princípios e das posturas estratégicas que serão ressaltados pela United Nations Environmental Programme (UNEP), World Tourism Organization (UNWTO), World Travel Tourism and Council (WTTC) e Global Reporting Initiative (GRI).

Outras perspectivas complementares aos valores propostos anteriormente, que estabelecem uma base de apoio à abrangência, à plenitude, à validade e à efetividade de gestões sustentáveis podem ser vistas nas propostas da International Organization for Standardization (ISO) e da Associação Brasileira de Normas e Técnicas (ABNT), destacando-se: ABNT NBR ISO 9.001 - Sistemas de Gestão da Qualidade; ABNT NBR ISO 14.001 - Sistemas de Gestão Ambiental; ABNT NBR ISO 26.000 - Diretrizes sobre Responsabilidade Social.

Nesse cenário, a ABNT (2006) estruturou uma normativa de sustentabilidade específica à hotelaria: ABNT NBR 15.401:2006. Essa apresentou requisitos ambientais, socioculturais e econômicos como preceitos norteadores à sustentabilidade hoteleira, tendo como objetivo principal a apresentação de requisitos fundamentais ao desempenho de uma gestão sustentável e tendo como referência básica ao seu processo de estruturação o Ciclo PDCA. Além dessa normativa, outro instrumento relevante, que se atrela ao debate da sustentabilidade hoteleira, é ofertado pelo Instituto de Hospitalidade (IH), sendo reconhecido como: NIH 54:2004 - Norma Nacional para Meios de Hospedagem: requisitos para a sustentabilidade.

Aspecto interessante a se mencionar é que, de acordo com esses dois últimos instrumentos, os indicadores de sustentabilidade podem ser criados pelos próprios gestores hoteleiros, já que esses precisam respeitar as especificidades territoriais que circundam seu estabelecimento. Contudo, os autores ressaltam a necessidade dessas normativas serem tomadas como um "norte diretivo", já que as mesmas abrem espaço para questionamentos relacionados à responsabilidade social interna, bem como as questões relacionadas ao universo político, espacial e cultural que se encontram inerentemente atreladas às propostas de desenvolvimento sustentável. Além disso, apropriando-se dos discursos de Perez e Del Bosque (2014), enfatiza-se aqui que a sustentabilidade 
deve levar em consideração uma abordagem mais holística, que leve em consideração, a priori, a relação delicada e dinâmica perpetrada entre quatro dimensões do desenvolvimento sustentável - econômica, cultural, social e ambiental - e as seis dimensões de gerenciamento dos stakeholders - cliente, fornecedor, empregado, distribuidor, sociedade e meio ambiente, como será exposto na Figura 1.

Essa nova abordagem para o estudo da sustentabilidade permite aos autores completar a proposta que tem sido usada até agora pela acadêmica e pelo mercado, e assim, propiciar um quadro mais detalhado do nível de desenvolvimento e implementação da sustentabilidade no setor hoteleiro. (PEREZ; DEL BOSQUE, 2014, p.204).

Figura 01: A estrutura da sustentabilidade na abordagem Desenvolvimento Sustentável e Gerenciamento dos Stakeholders"

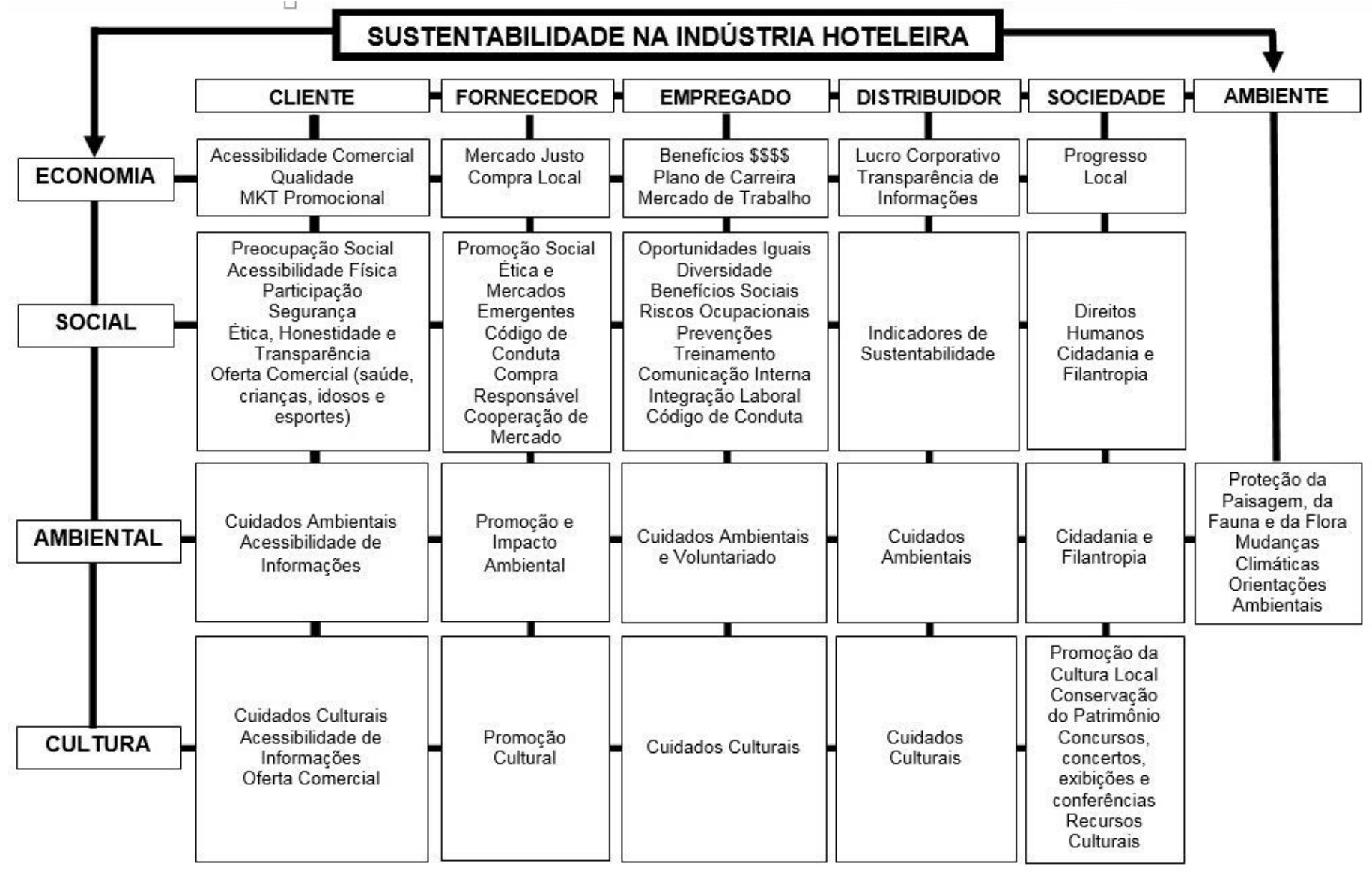

Fonte: (PEREZ e DEL BOSQUE, 2014) 
Com o intuito de se realizar um trabalho acadêmico que contribua efetiva e positivamente para a difusão de uma discussão que ressalte os reais sentidos e valores do desenvolvimento sustentável, a escolha por um estudo de caso em um dos cenários turísticos mais relevantes ao turismo nacional acarreta, sob o ponto de vista dos autores, certa credibilidade, veracidade e legitimidade frente aos anseios mercadológicos e científicos que estão no entorno da sustentabilidade hoteleira.

Quanto à localização do objeto estudado, o Rio de Janeiro é uma das unidades federativas do Brasil com maior representatividade no setor turístico nacional em termos de movimentação de turistas, oferta de meios de hospedagem e demais equipamentos que movimentam a cadeia produtiva do turismo. Com base no Anuário Estatístico do Turismo 2014 (MTUR, 2014), a Tabela 01 tem o intuito de expor dados relativos ao ano de 2013 e que são capazes de retratar o Estado do Rio de Janeiro em relação ao desenvolvimento do seu setor turístico.

Além da cidade do Rio de Janeiro - que por si só já oferece variada oferta turística pela diversidade cultural e pelas belezas naturais -, o Estado do Rio de Janeiro também conta com outras cinco regiões consideradas indutoras do desenvolvimento turístico, sendo estas: Serra da Mantiqueira, na Região Sul do Estado; Vale do Café, localizado ao Sul da capital do Estado; a Região Serrana; Costa Verde, no litoral sul; e a Região dos Lagos, também conhecida como Costa do Sol, que se situa ao norte da cidade do Rio de Janeiro (MTUR, 2014).

Tabela 01: Dados Estatísticos do Desenvolvimento Turístico no Eixo Rio - São Paulo ESTATÍSTICAS DO TURISMO - ANO BASE 2013

Chegadas Internacionais

Total

Via Rio de Janeiro

Via São Paulo

Via demais estados
5.813 .342

1.207 .800

2.219.513

2.386 .029
Movimentações nacionais em Aeroportos

Total

89.273 .472

11.181 .143

23.447 .024

São Paulo

54.645 .305 
Eventos Internacionais

$$
\begin{gathered}
\text { Total } \\
\text { Rio de Janeiro } \\
\text { São Paulo } \\
\text { Demais estados }
\end{gathered}
$$

317

79

70

168

\section{Oferta Hoteleira}

Total

835.747

Rio de Janeiro

87.553

São Paulo

108.041

Demais estados

640.153

Fonte: Ministério do Turismo (2014).

Ao se observar a Tabela 01, é possível perceber a relevante atuação do Rio de Janeiro nos resultados relativos ao desenvolvimento do turismo nacional. Dos quatro aspectos mencionados na tabela, o Estado do Rio de Janeiro apresenta significativo posicionamento em: (1) porta de entrada de aproximadamente $21 \%$ dos quase seis milhões de turistas internacionais; (2) a realização de $25 \%$ do número total de eventos internacionais que acontecerem no Brasil em 2013; (3) o posicionamento de aproximadamente 10,5\% da oferta hoteleira nacional; (4) e, por fim, 11\% das movimentações nacionais em aeroportos. Por conseguinte, pondera-se que o Rio de Janeiro se configura como um importante centro para o desenvolvimento do setor turístico nacional. Por sua vez, por ser um dos destinos brasileiros mais conhecidos internacionalmente, a capital do estado interfere diretamente nos resultados mostrados por atrair turistas de todo o mundo.

Com um pouco mais de uma década presente na cadeia produtiva hoteleira carioca, o JW Marriott Rio de Janeiro, bandeira de luxo da Rede Marriott de Hotéis, localiza-se no "coração" de Copacabana, à beira da Avenida Atlântica. A escolha desse empreendimento baseou-se em características próprias que o tornam expressivo para o desenvolvimento das atividades turísticas na cidade do Rio de Janeiro. A Tabela 02 tem o objetivo de apresentar, de maneira prática e direta, suas características: 
Tabela 02: JW Marriott Rio de Janeiro - Ficha Técnica

\begin{tabular}{|c|c|}
\hline \multicolumn{2}{|c|}{ Informações Gerais } \\
\hline Localização: & Avenida Atlântica, Copacabana \\
\hline Inaugurado em: & Abril de 2001 \\
\hline Origem: & Estados Unidos da América \\
\hline Administração: & Rede Internacional \\
\hline Segmentação: & Lazer/Corporativo \\
\hline Classificação: & Luxo \\
\hline \multicolumn{2}{|c|}{ Estrutura } \\
\hline Unidades Habitacionais: & 229 \\
\hline Suítes: & 16 \\
\hline Andares & 16 \\
\hline Salas de Eventos & 12 \\
\hline Piscina/ Sauna & 01 \\
\hline \multicolumn{2}{|c|}{ Outros Serviços e Facilidades } \\
\hline
\end{tabular}

Restaurante Terraneo (culinária internacional); The Carioca Bar; Estacionamento; Serviço de Valet, Academia, SPA, Lounge Executivo, Business Center, Conciergerie.

Fonte: Elaboração dos autores.

Dessa maneira, exposto o objeto de estudo, os autores analisaram - por meio de uma entrevista semiestruturada realizada com o Diretor de Engenharia da JW Marriott Rio de Janeiro - as práticas de sustentabilidade desse empreendimento, conforme os princípios expostos na fundamentação teórica deste trabalho, buscando-se compreender posturas, princípios, valores e ações que o referido estabelecimento possui frente à temática da sustentabilidade. Deste modo, o resultado dessa análise será exposto a seguir.

\section{DIMENSÃO INSTITUCIONAL}

A dimensão institucional, dentre as demais que serão discutidas no artigo, pode ser considerada o alicerce de uma gestão corporativa sustentável, já que neste momento as bases e as diretrizes que nortearão os programas de sustentabilidade são criadas e difundidas dentro e fora do ambiente organizacional. Para Silva e Cheaz (2001, p. 6), deverá ser entendida como:

[...] conjunto de todas as regras formais e informais que moldam a natureza de sua identidade, influenciam a intensidade e qualidade 
de sua dinâmica e direcionam os compromissos associados ao seu propósito. Entre estas regras do jogo se encontram as leis, políticas, premissas, enfoques, planos, prioridades, estratégias, normas, mecanismos institucionais, etc.

Assim, ela pode ser entendida como parte essencial dos valores corporativos que exprimem a relação da organização com sua comunidade e clientes internos/ externos. Por ter a premissa da hospitalidade como seu principal expoente já que o lema do J.W. Marriott é: "Cuide dos funcionários e eles cuidarão dos seus clientes" -, os colaboradores são tratados como "associados". O objetivo dessa nomenclatura reside na intenção de que os funcionários se sintam como partes efetivas, essenciais e cruciais ao rendimento operacional e financeiro do estabelecimento. Esse aspecto é tão relevante à gestão do JW Marriott do Rio de Janeiro que sua mensuração está presente no Balanced Scorecard da empresa.

Como forma de avaliação e controle da satisfação de seus associados, tal estabelecimento hoteleiro participa anualmente de uma pesquisa realizada pelo Instituto Great Place to Work, que avalia e premia as empresas que possuem os melhores ambientes laborais. No ano de 2014 o hotel foi eleito "a Melhor Empresa para se trabalhar no Rio de Janeiro" (GREAT PLACE TO WORK, 2014).

Nesse sentido, a satisfação dos clientes, sejam eles internos ou externos, é entendida aqui como elemento fundamental para a aplicação da responsabilidade social, vista aqui como um dos elementos chave para a construção de uma imagem e identidade empresarial capaz de estrategicamente dispor uma organização em posição de destaque mercadológico (MARTINEZ; PEREZ; DEL BOSQUE, 2014), tal qual pode ser visto na premiação mencionada anteriormente. Ainda considerando as ações institucionais, visando manter e aprimorar a sustentabilidade do hotel, trazendo benefícios não apenas ao âmbito corporativo, mas também à comunidade e ao meio ambiente local, os gestores do JW Marriott Rio de Janeiro reúnem-se periodicamente com gestores de outros estabelecimentos hoteleiros de sua região para discutir políticas e medidas de redução de consumo de energia, de água e de materiais, como papel de escritório.

A relação dos gestores e dos colaboradores do JW Marriott Rio de Janeiro com atores externos pode ser vista também na participação da empresa em eventos cuja temática se volta para a questão da sustentabilidade, como, por 
exemplo, o Clean Up the World. Os organizadores dessa atividade apresentam campanhas comunitárias de mutirões de limpeza, conservação e proteção do meio ambiente, o que acaba por incentivar, por parte do JW Marriott Rio de Janeiro, a realização de mutirões entre seus associados e organizações não governamentais para a limpeza de parte da praia de Copacabana.

\section{DIMENSÃO AMBIENTAL}

Considerando esforços, ações e programas que têm como objetivo final a diminuição dos impactos negativos causados pela operacionalização do hotel JW Marriott Rio de Janeiro, seus gestores internacionais criaram um programa chamado The JumaSustainable Development Reserve(MARRIOTTINTERNATIONAL, 2014). Essa ação teve início em 2008, sendo uma tentativa de propor a diminuição da emissão de dióxido de carbono e demais gases que podem causar prejuízos à biodiversidade e à vida da humanidade na Terra. Sediado no estado brasileiro do Amazonas, a iniciativa - que leva o nome de Juma por ser desenvolvido na reserva de Juma, na cidade de Novo Aripuanã - objetiva proteger a floresta e toda sua biodiversidade, principalmente dos impactos oriundos da agricultura e da extração ilegal de madeira observados nesta região.

Figura 02: Programa "The Juma Sustainable Development Reserve"
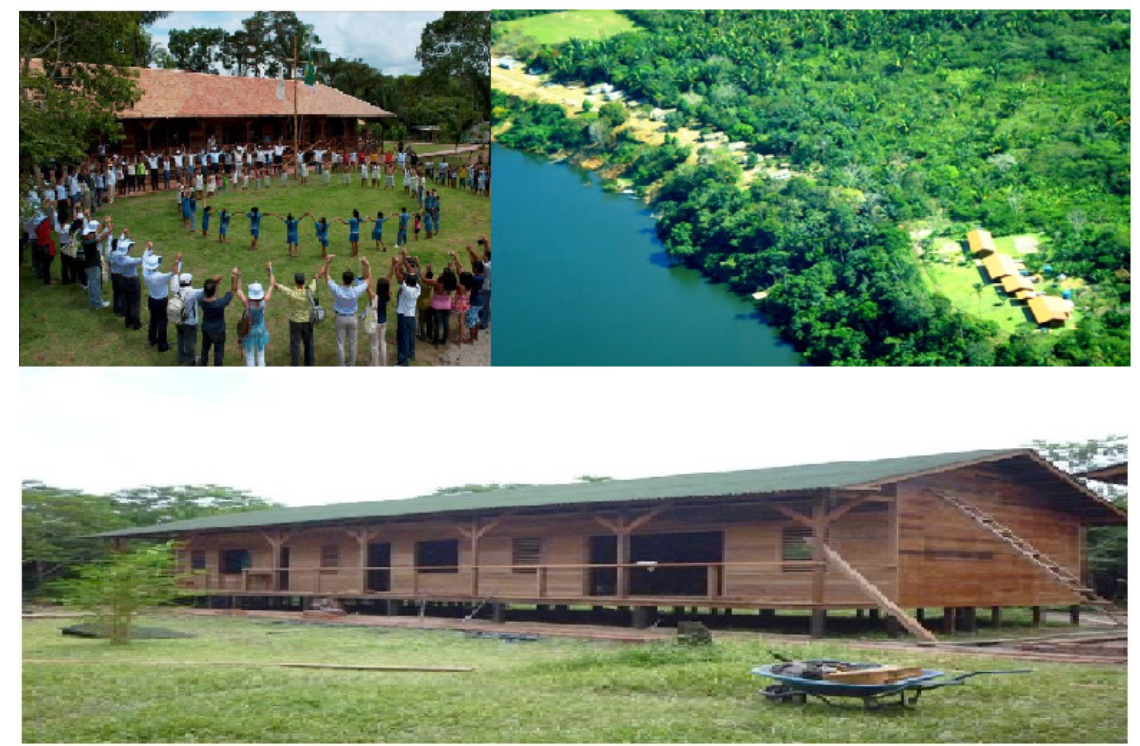

Fonte: Marriott International (2014). 
Retornando à Copacabana, local onde se situa o Hotel JW Marriott Rio de Janeiro, o entrevistado ressalta a existência de um programa de doação de aproximadamente 1.500 garrafas pet por semana à Colônia de Pescadores Z-13 que atua, desde o bairro da Urca até o Pontal do Recreio dos Bandeirantes, em um projeto de reciclagem, evitando que esses materiais descartáveis sejam depositados em lugares impróprios e que prejudiquem suas atividades pesqueiras.

Sobre o destino final de resíduos, todo lixo é descartado de acordo com os preceitos do Sistema de Manifesto de Resíduos. O sistema propõe o controle dos resíduos gerados no Estado do Rio de Janeiro, da sua origem até seu destino final, impedindo que estes sejam depositados em locais inapropriados (INEA, 2004). Assim, todos os resíduos do hotel são direcionados aos lugares apropriados, estabelecidos pelo Governo do Estado.

Autilização de recursos hídricos, elétricos e a emissão de gases poluentes também estão incluídas na lista de prioridades do hotel, conforme ressalta o entrevistado. Como forma de mensuração do consumo desses elementos e do volume de gases emitidos, o meio de hospedagem associou-se ao "Green Hotel Global", que oferece um sistema próprio que auxilia a redução do consumo de água, energia e emissão de gases. Por meio deste sistema torna-se possível apresentar um relatório de consumo e desperdício do estabelecimento por um evento isolado, ou até mesmo por uma unidade habitacional (GREEN HOTEL GLOBAL, 2014).

Como forma de se sensibilizar o hóspede frente à importância desses cuidados, em cada unidade habitacional são encontrados informativos que esclarecem, por exemplo, o porquê de não se trocar a roupa de cama e banho diariamente. Essas ações, por mais simples que se mostrem, fazem com que estes sujeitos também tenham, caso façam a adesão por essas práticas, uma parcela significativa de contribuição e esforço para a preservação dos recursos naturais.

Sobre a estrutura física, objetivando a redução do consumo de energia do hotel, um grande vitral localizado no topo deste estabelecimento permite a entrada de luz natural, evitando que um maior número de luzes fique aceso durante o dia. Esse atrium também é fundamental para que as unidades habitacionais que não possuem vista para o mar tenham acesso à luz do dia. 
Figura 03: Paredes de Vidro ${ }^{1}$

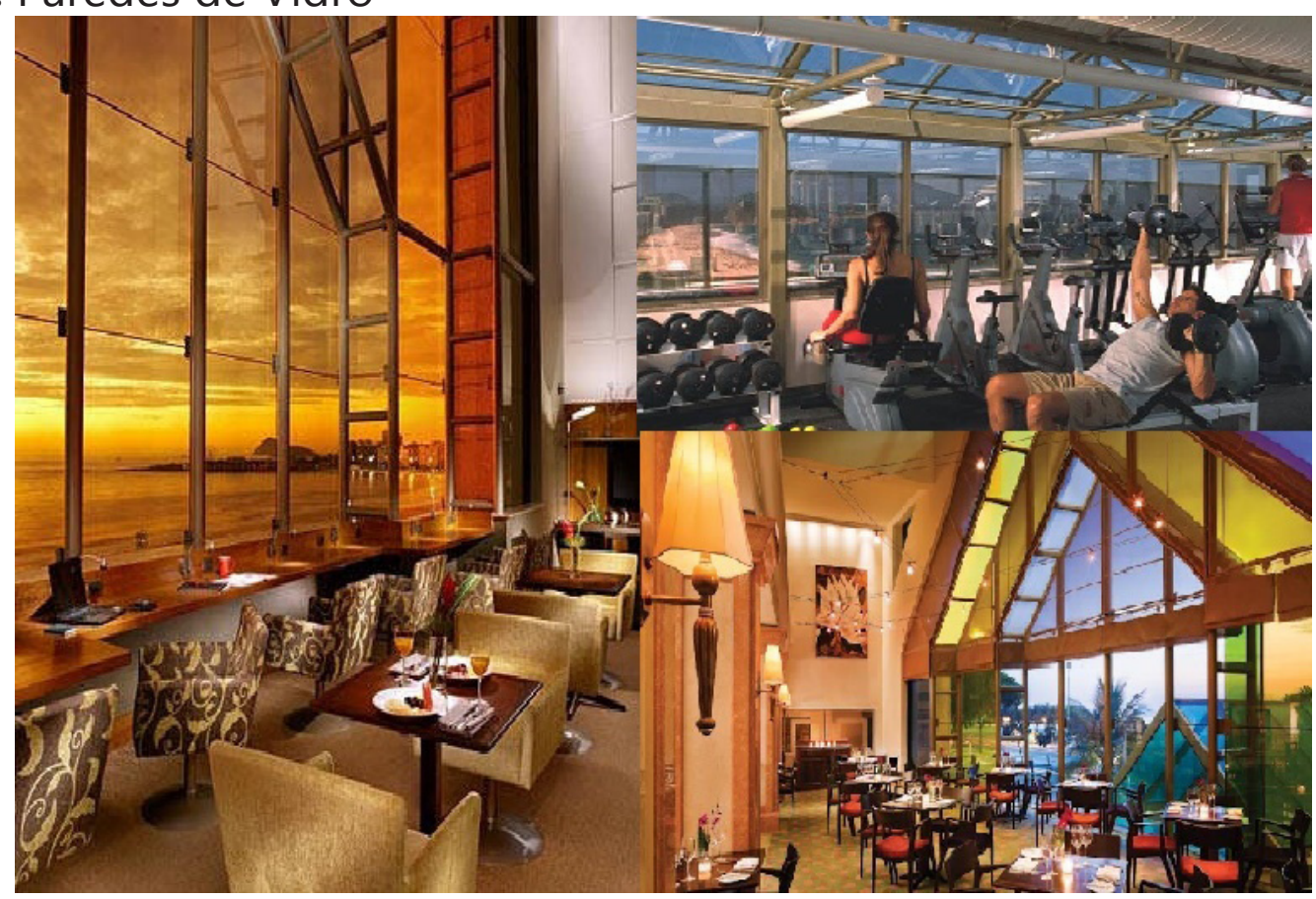

DIMENSÃO SOCIOCULTURAL

Já que a esfera sociocultural da sustentabilidade turística engloba os efeitos sobre uma dada população, há a possibilidade de se ponderar que o impacto sociocultural pode se manifestar "através de uma gama enorme de aspectos, desde as artes e o artesanato, até o comportamento fundamental de indivíduos e grupos" (COOPER, 2007, p. 238). Dito isso, na presente etapa dessa pesquisa os autores apresentarão os programas realizados pelo JW Marriott Rio de Janeiro que, segundo o entrevistado, exercem um impacto positivo sobre sua comunidade.

Nesse contexto, destaca-se o "Spirit to Serve", um dos valores organizacionais tido como "norteador" para os programas desenvolvidos periodicamente pelo hotel. Esse valor é baseado no suporte à comunidade em cinco campos de atuação, sendo estes: (1) diminuição da pobreza; (2) proteção ao meio ambiente; (3) desenvolvimento da força de trabalho local; (4) bem-estar infantil; e a (5) inclusão social (respeito às diversidades) (MARRIOTT INTERNACIONAL, 2012).

Como um programa contínuo de auxílio na formação e no desenvolvimento da mão de obra local, o JW Marriott Rio de Janeiro participa do programa "Youth Career Initiative2", que oferece curso de formação técnica e teórica 
sobre hospitalidade para jovens que se formaram no ensino médio. Além das aulas operacionais, os alunos passam por períodos determinados em cada departamento, para se familiarizarem com as particularidades do dia a dia operacional hoteleiro. Outro aspecto interessante do programa sãos as aulas de etiqueta e idiomas ministradas pelos próprios colaboradores que se candidatam, voluntariamente, à aplicação deste curso. Ao término desse programa, os alunos que mais se destacam têm a oportunidade do primeiro emprego no próprio estabelecimento hoteleiro. Por meio de um breve depoimento coletado e de uma entrevista semiestruturada, soube-se que uma das alunas da turma YCI JW Marriott Rio de Janeiro do ano de 2013 agora atua como Jovem Aprendiz na recepção do hotel. Nota-se que:

"O programa YCI foi uma oportunidade única em minha vida, pois sempre estudei turismo, mas não tinha posto em prática. Passar por todos os setores, aprender um pouco de cada na prática é maravilhoso. Agora tenho noção de como cada setor age, como funciona no dia a dia, coisas que poucos têm. As aulas teóricas, como Inglês, etiqueta, Espanhol que complementavam a prática foi o diferencial para o meu desenvolvimento no programa."

Nayara dos Santos de Jesus, 20 anos - YCI 2013

Outro ponto interessante e que vai ao encontro de uma das facetas da identidade cultural carioca pode ser demonstrado na preocupação, por parte do comitê executivo, em fazer com que a estrutura do ambiente hoteleiro não destoasse da cultura local. Ao surgir a necessidade de renovação do lobby do hotel, optou-se por fazê-lo de forma que este pudesse traduzir a essência do que os gestores do hotel entendem como "jeito carioca de viver". Para isso, os associados foram incentivados a dar opiniões sobre o que seria "esse jeito", resultando na inserção de um bar conhecido como "The Carioca Bar", que oferece comidas leves, rápidas e práticas com ingredientes tipicamente brasileiros, além de drinks e lanches.

\section{DIMENSÃO ECONÔMICA}

Por último, nessa etapa são relacionadas algumas ações que possuem como objetivo a maximização dos lucros da organização. Dito isso, vale ressaltar que 
grande parte das políticas e dos programas citados no trabalho objetivam, além de possíveis mitigações de efeitos negativos causados ao meio ambiente, aos colaboradores ou à comunidade em geral, ofertar um maior retorno financeiro ao estabelecimento hoteleiro.

$\mathrm{Na}$ indústria da hospitalidade, o impacto negativo dos hotéis ao meio ambiente tem chamado atenção dos clientes. Nas últimas décadas, a demanda por estabelecimentos responsáveis cresceu rapidamente. Indubitavelmente, a sustentabilidade é considerada como uma das peças chave na indústria mundial de hospedagem. Considerando que os clientes de hoje são altamente sensíveis aos problemas ambientais a ponto de mudar seus hábitos de consumo, minimizar os impactos ambientais negativos produzidos pelas operações hoteleiras vem se tornando essencial para a manutenção da competitividade ou para se obter vantagens competitivas em seu mercado de atuação. (HAN; YOON, 2015, p.22).

Desta maneira, julga-se importante mencionar que a satisfação dos associados interfere diretamente no retorno financeiro da empresa por diversos motivos. Como já mencionado anteriormente, o colaborador satisfeito consegue oferecer serviços cada vez mais qualitativos aos hóspedes, gerando alto grau de excelência, encantamento e, posteriormente, a fidelização desses clientes. Castelli (2005) enfatiza que esse cenário, da satisfação e da capacitação dos colaboradores, está diretamente relacionado à diminuição dos gastos com contratação de novos funcionários e do declínio no percentual de demissões da organização analisada. Obviamente, uma empresa que consegue oferecer aos seus funcionários benefícios e condições de trabalho favoráveis terá uma menor rotatividade de mão de obra (turnover). Nesse sentido, Davis e Newstrom (1992) identificam que, além do turnover, a insatisfação dos colaboradores pode ter como consequência absenteísmo, conflitos internos, não comprometimento com os objetivos da organização, desperdício de materiais e baixa qualidade no serviço.

Outra ação capaz de evitar que gastos extras sejam despendidos é a política de redução de acidentes de trabalho aplicada pelo hotel. Com essa política espera-se evitar os gastos advindos do afastamento de colaboradores, tais como os custos relativos à contratação temporária, os esforços despendidos para treinamento de novos colaboradores e a perda temporária ou permanente de um associado 
qualificado. O entrevistado destaca que, por meio de uma concisa política de minimização de acidentes ocupacionais, evitam-se também prejuízos e danos aos equipamentos e aos utensílios utilizados no hotel. Dentre as ações aplicadas para evitar esses acidentes, destaca-se a utilização de Procedimentos Operacionais Padrão (POP's), que inibem a utilização de materiais, de equipamentos, de utensílios e a realização de atividades de maneira inapropriada.

A existência de um plano de negócios bem definido, com estratégias, metas e planos de ação é fundamental para que o hotel tenha o retorno financeiro desejado. Para isso a análise dos concorrentes e o posicionamento do hotel no mercado (segmentação) são fatores relevantes. Observando o meio de hospedagem estudado, é possível verificar que há uma segmentação bem estabelecida, sendo neste caso o público corporativo. Pode-se perceber que a estrutura, os serviços e as facilidades oferecidos pelo meio de hospedagem são pensados e voltados para as necessidades do perfil do cliente que viaja a trabalho.

\section{ANÁLISE SWOT}

A Tabela 03 apresenta a análise SWOT do Hotel JW Marriott, concebida com base nos dados coletados e expostos anteriormente. Tal instrumento permitirá ao leitor observar fatores e características internas e externas que influenciam na tomada de decisões de uma organização, no planejamento estratégico e na sua operacionalização. Para Chiavenato (2005), a matriz SWOT permite que a empresa identifique a melhor maneira de trabalhar com as oportunidade e as ameaças, oriundas do ambiente externo à organização e, a partir deste cenário, elaborar estratégias de desenvolvimento, ataque ou manutenção, as quais serão criadas de acordo com estas informações.

Tabela 03: Análise SWOT do Hotel JW Marriott Rio de Janeiro

\begin{tabular}{|c|c|}
\hline \multicolumn{2}{|c|}{ ANÁLISE SWOT- HOTEL JW MARRIOTT RIO DE JANEIRO } \\
\hline \multicolumn{2}{|c|}{ ANÁLISE INTERNA } \\
\hline STRENGHTS (FORÇAS) & WEAKNESSES (FRAQUEZAS) \\
\hline Rede Internacional & Rede Internacional \\
\hline Relação entre empresa e "associados" & Estrutura: pouca luminosidade nas UH's \\
\hline Satisfação dos associados (controle) & Estrutura: falta de adaptação nas UH's \\
\hline Satisfação dos hóspedes (controle) & Estrutura: falta de adaptação banheiros \\
\hline
\end{tabular}


Cultura e valores organizacionais

Plano de negócios, estratégia e metas

Interação com concorrência

Comitê interno para sustentabilidade

Desenvolvimento de projetos contínuos

Ação de macro abrangência

Apoio a projetos locais

Políticas de sustentabilidade estruturadas

Planejamento para descarte de resíduos

Controle do consumo de água e energia

Políticas ambientais

Aspectos específicos da estrutura

Envolvimento dos associados

Associação às instituições internacionais

Revenue Management
Serviços oferecidos e categoria do hotel

Política de contratação

Ações voltadas aos hóspedes

Utilização de produtos locais

Produtos/fornecedores sustentáveis

Piscina

Água de reuso

ANÁLISE EXTERNA

OPPORTUNITIES (OPORTUNIDADES)

THREATS (AMEAÇAS)

Preocupação mundial com questões ambientais

Divulgação das ações dos concorrentes

Incentivos governamentais

Eventos de cunho sustentável

Saídas de esgoto na orla de Copacabana

Água do mar imprópria para banho

Rio de Janeiro como foco mundial (grandes eventos)

Violência do entorno

Organizações social e ambientalmente responsáveis Preços praticados pela hotelaria no Rio de Janeiro Green Hotel Global

\section{CONSIDERAÇÕES FINAIS}

A partir desse artigo é possível compreender que a cadeia produtiva do turismo perpassou por processos peculiares em seu desenvolvimento, sendo observado, como relata Molina (2003), que sua operacionalização ressaltaria os aspectos econômicos, a priori, para, em seguida, gestores e pesquisadores perceberem a relevância das facetas culturais, sociais, políticas, espaciais e ambientais que estão intimamente atreladas ao seu desenvolvimento (BENI, 2007; KRIPPENDORF, 2001; PEREZ; DEL BOSQUE, 2014). Assim, por meio dos resultados e das discussões estabelecidas nesse estudo, é possível verificar a relação indissociável que o processo de planejamento turístico possui com os princípios, valores e condutas pregados pela premissa do desenvolvimento sustentável. 
Pelo fato de o turismo não apenas ser influenciado pelos preceitos apontados, como também por exercer uma forte influência - positiva e/ou negativa - econômica, sociocultural, política e ambiental em sua territorialidade, todo e qualquer processo de gestão de suas atividades, e nisso a hotelaria se faz presente, deverá apresentar uma conduta que leve em consideração os impactos produzidos e a sua relação com a tríade turística (CHEN, 2015) - intitulada aqui como turistas, empreendedores e comunidade local - e os stakeholders (PEREZ; DEL BOSQUE, 2014) que sustentam a operacionalização destas mesmas atividades.

Nesse sentido, analisando o setor turístico e as dimensões que constituem o conceito de sustentabilidade, pondera-se nesse estudo a necessidade de se estabelecer uma estreita relação entre ambos, já que a sustentabilidade é vista como principal fator de preservação dos recursos naturais e culturais em que a atividade turística é desenvolvida. Exposto isso, o trabalho em questão analisou, pela ótica do estudo de caso, os programas e as ações sustentáveis desenvolvidos pelo JW Marriott Rio de Janeiro, acreditando, por meio dessa metodologia, ter obtido a qualidade e a robustez necessária (YIN, 1989) que possibilitam os autores a afirmar a existência de uma "construção válida pela utilização de múltiplas fontes de evidência (ou triangulação de evidências) e por ter informantes externos chave para subsidiar o relatório de estudo de caso" (MARTINEZ; PEREZ; DEL BOSQUE, 2014, p. 56).

Durante o desenvolvimento do presente estudo de caso foi possível analisar os indicadores de sustentabilidade do hotel pesquisado, por intermédio de entrevistas semiestruturadas realizadas com o colaborador responsável pelos programas de sustentabilidade do meio de hospedagem, os quais se mostraram cruciais para a identificação das práticas sustentáveis dessa organização, além, é lógico, da observação participante de um dos autores do texto.

Assim, a partir da análise dos indicadores de sustentabilidade do hotel, constatou-se que há, por parte dos gestores do J.W. Marriott Rio de Janeiro, uma preocupação com os impactos de suas atividades sobre a comunidade e o meio ambiente local. Dentre os programas realizados pelo hotel, identificaramse ações que contemplam as esferas econômica, sociocultural, ambiental e 
institucional da sustentabilidade, tal qual explica Perez e Del Bosque (2014). Percebeu-se também que seus gestores entendem a relação de dependência entre o empreendimento e os recursos naturais, sociais, culturais e materiais da localidade e que, por esse motivo, existe um esforço para contribuir positivamente para o desenvolvimento da região.

Notou-se também que os valores organizacionais dessa empresa são propícios para o desenvolvimento de ações sustentáveis. Contudo, ainda que o hotel apresente indicadores de sustentabilidade que se mostram satisfatórios do ponto de vista de uma gestão sustentável, os tópicos a seguir representam algumas ações que poderiam ser aprimoradas pelo hotel:

(1) A aquisição da certificação ISSO 14.001 que define as ações de um sistema de gestão ambiental e da ABNT NBR 15.401, bem como a NIH 54:2004, que estabelece requisitos para uma gestão sustentável aos meios de hospedagem;

(2) Adaptação das unidades habitacionais (UH's) e das áreas sociais para a diminuição do consumo, bem como o desperdício de energia e de água. Dentre as adaptações, destacam-se: a utilização de sensor de presença para a iluminação de áreas públicas; a iluminação das UH's vinculada ao cartão chave do hóspede; e a utilização de torneiras e chuveiros com sensor de presença;

(3) A concepção de programas independentes, criados pelos gestores locais (sem a necessidade de intervenção da rede) em sistemas de parceria com outros empreendimentos e esferas públicas e que sejam voltados às necessidades da comunidade. Como exemplo, cita-se aqui a possibilidade da criação de uma ação comunitária que estimule a retirada dos jovens do cenário de violência tão exacerbada no município carioca;

(4) Apresentação de uma taxa percentual a ser atingida na contratação de mão de obra local, oriunda principalmente das comunidades localizadas no entorno do hotel;

(5) Estabelecimento de metas - percentual - para a utilização de produtos de fornecedores locais, comprometidos com as questões da sustentabilidade;

(6) Implantação de um sistema de água de reuso; 
(7) Implementação de ações de conscientização para os hóspedes, tais como informações sobre o meio ambiente local, dicas de comportamento adequado perante os atrativos turísticos que provavelmente serão visitados e incentivos à separação do lixo para a reciclagem.

Um dos intuitos dessa pesquisa se deu na possibilidade de transparecer lacunas relevantes ao processo de instauração de gestões sustentáveis atreladas à cadeia produtiva do turismo. Pesquisas futuras devem começar a buscar a proposição de um debate mais amplo acerca de aspectos como: (1) Responsabilidade Social Interna; (2) gestões participativas que se mostram cruciais à proposta de desenvolvimento responsável, justo e equilibrado; (3) a instauração de uma gestão baseada nas dimensões da sustentabilidade - social, cultural, econômica, política, espacial e ambiental - atrelada às percepções do gerenciamento dos stakeholders, para que assim se mensure o grau e a amplitude dos impactos oriundos do turismo. Para tanto, há um convite aqui para que análises gerenciais e acadêmicas comecem a avançar, indo além das conotações ambientais e socioeconômicas observadas em boa parte dos trabalhos acadêmicos, bem como nas normativas, certificações e legislações que expõem critérios para inserção, desenvolvimento e operacionalização de gestões sustentáveis aplicadas ao turismo e à hotelaria.

\section{REFERÊNCIAS}

ACCOR. Planet 21. Disponível em: http://www.accorhotels.com/pt-br/sustainabledevelopment/index.shtml. Acesso em: 02 ago. 2014.

ACSELRAD, H. Sentidos da sustentabilidade urbana. Rio de Janeiro: DP\&A, 2001.

AGÊNCIA DE PROMOÇÃO DE INVESTIMENTOS DO RIO DE JANEIRO. Hotelaria no Rio de Janeiro. Disponível em: http://rio-negocios.com/hotelaria-no-rio/. Acesso em: 15 nov. 2013.

ASSIS, M. Obras completas. Rio de Janeiro: Editora Nova Aguilar, 1994.

ASSOCIAÇÃO BRASILEIRAS DE NORMAS TÉCNICAS - ABNT. Norma Técnica - ABNT NBR 15.401 - Meios de Hospedagem - Sistemas de Gestão da Sustentabilidade - Requisitos. Rio de Janeiro: ABNT, 2006. 
BARTHOLO, R.; SANSOLO, D. G.; BURSZTYN, I. Turismo de base comunitária: diversidade de olhares e experiências brasileiras. Rio de Janeiro: Letra e Imagem, 2009.

BENI, M. C. Política e planejamento de turismo no Brasil. São Paulo: Aleph, 2006.

BENI, M. C. Análise Estrutural do Turismo. São Paulo: SENAC, 2007.

CASTELLI, G. Excelência em hotelaria: uma abordagem prática. Rio de Janeiro: Qualitymark, 2005.

CHEN, J. Tourism stakeholders' attitudes toward sustainable development: a case in the Artic. Journal of Retailing and Consumer Services, v.22, n.1, p.225-230, 2015.

CHIAVENATO, I. Administração nos novos tempos. Rio de Janeiro: Elsevier, 2005.

CHOU, C. Hotel's environmental policies and employee personal environmental beliefs: interactions and outcomes. Tourism Management, v.40, n.1, p.436-446, 2014.

COOPER, C. Turismo: princípios e práticas. Porto Alegre: Bookman, 2007.

DAVIS, K.; NEWSTRON, J.W. Comportamento humano no trabalho. São Paulo: Pioneira, 1992.

GREAT PLACE TO WORK. Melhores empresas para se trabalhar - Rio de Janeiro. Disponível em: http://www.greatplacetowork.com.br/melhores-empresas/gptw-rio-de-janeiro. Acesso: 18.nov.2014.

FRAJ, E.; MATUTE, J.; MELERO, I. Environmental strategies and organizational competitiveness in the hotel industry: The role of learning and innovation as determinants of environmental success. Tourism Management, v.46, n.1, p.30-42, 2015.

GALPIN, T.; WHITTINGTON, J.L.; BELL, G. Is your sustainability strategy sustainable? Creating a culture of sustainability. Corporate Governance, v.15, n.01, p.1-17, 2015.

HAIR JR., J. F. et al. Análise Multivariada de Dados. São Paulo: Bookman, 2009.

HAN, H.; YOON, H. J. Hotel customers' environmentally responsible behavioral intention: Impact of key constructs on decision in green consumerism. International Journal of Hospitality Management, v.45, n.01, p.22-33, 2015.

KRIPPENDORF, J. Sociologia do Turismo: para uma nova compreensão do lazer e das viagens. São Paulo: Aleph, 2001.

LANDER, E. A colonialidade do saber: eurocentrismo e ciências sociais. In: ARTURO, E. O 
DoI: 10.14210/rtva.v17n2.p444-474

lugar da natureza e a natureza do lugar: globalização ou pós-desenvolvimento. Buenos Aires, Argentina: CLASCO, 2005.

LEMOS, A. I. G. de (Org.). Turismo: impactos socioambientais. São Paulo: Hucitec, 2001.

MARTÍNEZ, P.; PÉREZ, A.; DEL BOSQUE, I. R. Exploring the Role of CSR in the Organizational Identity of Hospitality Companies: A Case from the Spanish Tourism Industry. Journal of Business Ethics - Springer, v.124, n.1, p.47-66, 2014.

MARRIOTT INTERNATIONAL. Principles of Responsible Business - Environment Principles. October 2012. Disponível em: http://www.marriott.com/Multimedia/PDF/ CorporateResponsibility/Marriott_Environment_Principles.pdf. Acesso em: 18.set.2014.

MARRIOTT INTERNATIONAL. Amazon Rainforest - Juma. Disponível em: http://www. marriott.com/corporate-social-responsibility/jumareserve.mi. Acesso: 10.out.2014.

MINISTÉRIO DO TURISMO. Anuário Estatístico do Turismo - 2014. Disponível em: http:// www.dadosefatos.turismo.gov.br/dadosefatos/anuario/index.html. Acesso em: 18 set. 2014.

MOLINA, S. O pós-turismo - dos centros turísticos industriais para as ludópolis. São Paulo: Aleph, 2003.

NEVES FILHO, N. C. Relatório das oficinas de sensibilização ambiental - Programa Estratégico de Turismo Sustentável de Base Comunitária, Rio de Janeiro, 1999.

NOBRE, M. Desenvolvimento Sustentável: institucionalização de um conceito. Brasília-DF: Editora IBAMA, 2002.

ORGANIZAÇÃO MUNDIALDE TURISMO. Guia de desenvolvimento do turismo sustentável. Porto Alegre: Bookman, 2003.

PÉREZ, A.; DEL BOSQUE, I. R. Sustainable Development and Stakeholders: A Renew Proposal for the Implementation and Measurement of Sustainability in Hospitality Companies. Knowledge and Process Management, v.21, n.3, p.198-205, 2014.

PERES Jr., M. R.; REZENDE, D. Gestão da sustentabilidade no segmento hoteleiro: estudo dos meios de hospedagem de Monte Verde, MG. Caderno Virtual de Turismo. Rio de Janeiro, v. 11, n. 2, p.234-252, ago. 2011.

RIBEIRO, A. P. Jones Lang LaSalle aponta crescimento da rede hoteleira. IN: Revista Exame: Editora Abril, 2013. Disponível em: http://exame.abril.com.br/brasil/noticias/joneslang-lasalle-aponta-crescimento-da-rede-hoteleira. Acesso: 15 nov. 2013. 
ROBSON, C. Real World Research Design: a resource for users of social research methods in applied settings. 3rd. Ed. West Sussex: John Wiley \& Sons, Ltd, 2011.

ROTHMAN, F. D. O estudo de caso como método científico de pesquisa. In: $1^{\circ}$ Simpósio de Economia Familiar. Economia familiar: uma olhada sobre a família nos anos 90. Viçosa: Imprensa Universitária, 1994.

SACHS, I. Caminhos para o desenvolvimento sustentável. Ed. Garamond, Rio, 2000.

SANTOS, R. A. dos; EMILIANO, A. S.; PAGAMISSE, M. Discussões sobre a prática do turismo em ambientes naturais: arguições por uma gestão participativa capaz de contemplar princípios para o usufruto sustentável de espaços rurais. Revista Científica Eletrônica de Turismo, ano 09, n.17, p.1-11, 2012.

SILVA, J. S.. CHEAZ, J.; ROMERO, J. La dimensión institucional del desarrollo sostenible. São José (Costa Rica): Isnar, 2001.

SINGH, T.V. Tourism and development: not an easy alliance. In: GHOSH, R.N.; SIDDIQUE, M.A.B; GABBAY, R. (Eds.). Tourism and Economic Development: Case Studies from the Indian Ocean Region. Farnham: Ashgate Publishing, 2003.

SINGLETON JR, R. A.; STRAITS, B. C. Approaches Social Research. 5th Ed. Oxford: Oxford University, Press, Inc., 2010.

SLOAN, P.; LEGRAND, W.; KAUFMANN, C. S. A survey of social entrepreneurial communitybased hospitality and tourism initiatives in developing economies. A new business approach for industry. Worldwide Hospitality and Tourism Themes, v.06, n.1, p.51-61, 2014.

UNITED NATIONS ENVIRONMENT PROGRAMME (UNEP); WORLD TOURISM ORGANIZATION (UNWTO).2005. Making Tourism More Sustainable - A Guide for Policy Makers. Disponível em: http://www.unep.fr/shared/publications/pdf/DTIx0592xPA-TourismPolicyEN.pdf. Acesso em: 15 out. 2014.

VEIGA, J. (Org.). O Prelúdio do Desenvolvimento Sustentável. In: OLIVA, Pedro M. Economia Brasileira: Perspectivas do Desenvolvimento Sustentável. São Paulo: CAVC, 2005.

VON SIMSON, O. M. (Org.). Experimentos com história de vida. In: QUEIROZ, M. I. P. Relatos orais: do "indizível" ao "dizível". São Paulo: Vértice Editora Revista dos Tribunais, 1998.

YIN, Robert. K. Case study research: Design and methods. Applied Social Research Methods Series. Newbury Park: Sage Publications, 1989. 
1 Disponível em: http://www.marriott.com/hotels/hotel-information/travel/riomc-jw-marriotthotel-rio-de-janeiro/. Acesso em: 29 out. 2014.

2 Iniciativa Internacional que oferece oportunidade de qualificação específica para o setor hoteleiro aos jovens recém-formados na escola e que ainda não possuem uma profissão. Disponível em: http://www.youthcareerinitiative.org/yci-reflects-on-ten-years-in-brazil/. Acesso: 05 nov.2014. 